\title{
Carcinoma verrucoso de pene desarrollado sobre un liquen plano. ¿una auténtica lesión preneoplásica?
}

\author{
C. Álvarez Álvarez, F. Meijide Rico*, L. Rodríguez González**, I. Antón Badiola, E. Zungri Telo*, \\ J. Antonio Ortiz-Rey
}

Servicios de Anatomía Patológica, Urología* y Dermatología**. Hospital Povisa. Vigo. Pontevedra.

Actas Urol Esp 2006; 30 (1): 90-92

\section{RESUMEN}

\section{CARCINOMA VERRUCOSO DE PENE DESARROLLADO SOBRE UN LIQUEN PLANO. ¿UNA AUTÉNTICA LESIÓN PRENEOPLÁSICA?}

Introducción: Hasta un 30\% de carcinomas epidermoides de pene se desarrollan sobre un liquen escleroso, mientras que hay muy pocos casos publicados en los que la lesión preexistente sea un liquen plano. Se presenta un carcinoma verrucoso de pene desarrollado sobre un área de liquen plano.

Caso clínico: Un varón de 53 años consultó por presentar un tumor exofítico en glande de 6 meses de evolución, que había crecido sobre una lesión biopsiada 2 años antes, y diagnosticada como liquen plano hipertrófico. Tras su extirpación, el diagnóstico histológico fue de carcinoma verrucoso.

Comentario: el desarrollo de cualquier variante de carcinoma epidermoide de pene sobre un liquen plano puede ser meramente casual, o por el contrario podría ser una transformación neoplásica del mismo.

Palabras clave: Pene. Liquen plano. Carcinoma verrucoso.

\section{ABSTRACT \\ VERRUCOUS CARCINOMA OF THE PENIS ARISING FROM A LICHEN PLANUS. A TRUE PRENEOPLASTIC LESION?}

Introduction: up to $30 \%$ of squamous cell carcinomas of the penis arise from a lichen sclerosus, but very few reports in which lichen planus was the preexisting lesion have been published. We report a male with verrucous carcinoma of penis that developed in an area of lichen planus.

Clinical case: a 53-year-old male presented with an exophytic tumor on the glans penis that had been present for about 6 months. The lesion developed in a previously biopsied area of lichen planus hypertrophicus. After excision, histological diagnosis was verrucous carcinoma.

Comment: the development of any subtype of squamous cell carcinoma of penis in a lichen planus can be coincidental, or a neoplastic transformation of lichen planus can take place.

Key words: Penis. Lichen planus. Verrucous carcinoma.

$\mathrm{L}$ os carcinomas verrucosos de pene son tumores extremadamente bien diferenciados, que causan grandes problemas de diagnóstico diferencial con otras entidades morfológicamente similares. Presentamos un caso de este tipo de tumor, que se desarrolló sobre un liquen plano previamente biopsiado y luego tratado con nitrógeno líquido. Tras dos años, en la misma zona surgió una neoplasia exofitica que fue diagnosticada como carcinoma verrucoso. Esta asociación es extremadamente infrecuente en el pene, no habiéndose descrito previamente en la literatura española, y existiendo sólo cinco casos de carcinomas epidermoides desarrollados sobre un liquen plano publicados en la literatura mundial, de los que sólo uno era del subtipo verrucoso ${ }^{1-4}$. 


\section{CASO CLÍNICO}

Varón de 53 años que consultó en el Servicio de Urología del Hospital POVISA por lesión de crecimiento exofitico en glande de seis meses de evolución. Dos años antes, al paciente se le había tomado una biopsia de una lesión papulosa con áreas eritematosas y brillantes, mal definida, situada en la misma zona, que fue diagnosticada histológicamente como liquen plano hipertrófico (Fig. 1). Posteriormente se trató la lesión residual con nitrógeno líquido, aunque sin conseguir su desaparición completa. En el momento actual, se realizó una exéresis completa de la tumoración, que medía 1 x 0,4 cm, y que microscópicamente tenía una arquitectura verrucosa, con una base ancha y un límite inferior muy bien definido. La lesión mostraba acantosis, papilomatosis e hiperqueratosis ortoqueratósica del epitelio, con papilas de tamaño similar, y ejes fibrovasculares casi inapreciables (Fig. 2). Desde el punto de vista citológico, las células tumorales mostraban mínima atipia citológica, sin presencia de mitosis ni cambios coilocíticos (Fig. 3). Se realizó estudio de biología molecular para detección y tipificación del virus del papiloma humano (VPH), que fue negativo. El diagnóstico fue carcinoma verrucoso de glande sobre un área previa de liquen plano hipertrófico.

\section{COMENTARIO}

El término liquen escleroso se prefiere actualmente sobre los de liquen escleroso y atrófico o

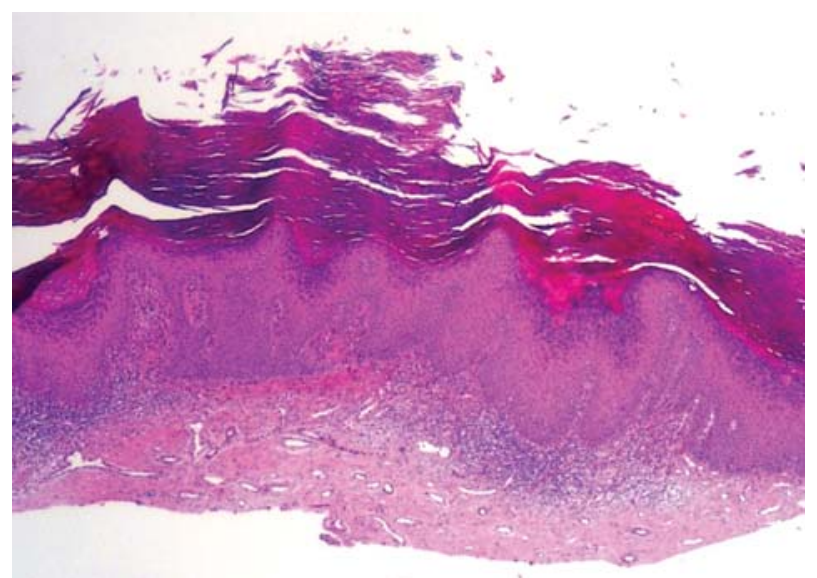

FIGURA 1: Imagen microscópica del liquen plano hipertrófico preexistente, que muestra un epitelio con hiperqueratosis ortoqueratósica, acantosis, y un infiltrado linfocitario liquenoide en la submucosa (hematoxilinaeosina, 25x).

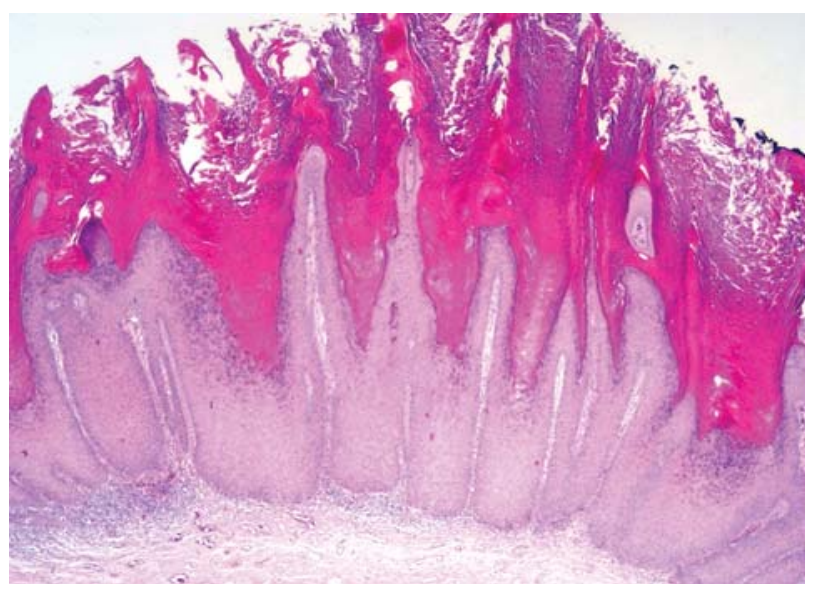

FIGURA 2: Microfotografia del carcinoma verrucoso, que presenta una arquitectura verruciforme con un limite inferior muy bien definido, y con ejes fibrovasculares muy finos en la submucosa (hematoxilina-eosina, 25x).

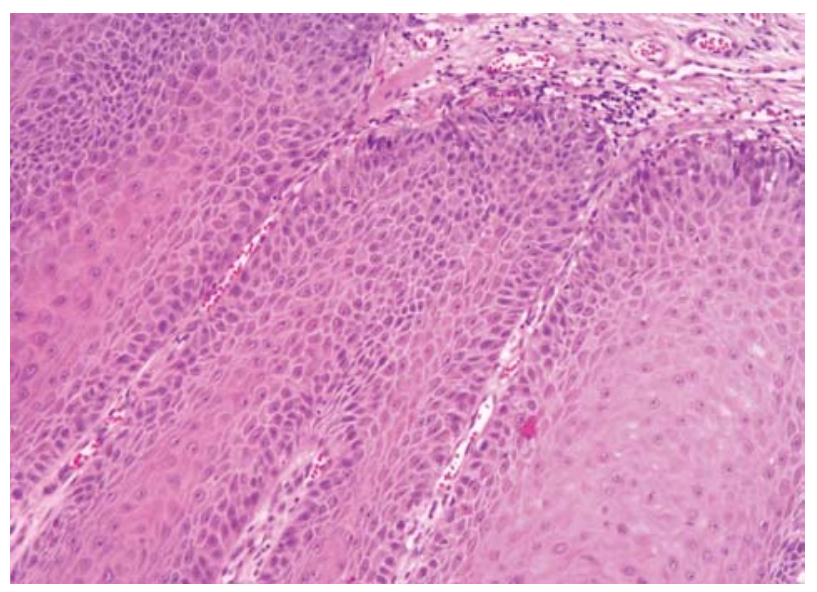

FIGURA 3: Imagen a mayor aumento de la neoplasia mostrando células tumorales con mínima atipia citológica, y sin cambios coilociticos (hematoxilina-eosina, 200x).

balanitis xerótica obliterante ${ }^{5}$ para definir una entidad que precede hasta a un 30\% de carcinomas epidermoides de pene, y que es considerada como una lesión preneoplásica, sobre todo en carcinomas no relacionados con infección por $\mathrm{VPH}^{5-7}$. El liquen plano es una lesión que afecta tanto a piel como a mucosas, entre ellas la de los genitales masculinos. Hasta la fecha únicamente se han publicado cinco casos en la literatura mundial en los que un carcinoma epidermoide de pene se haya desarrollado sobre un liquen plano, y sólo uno de ellos era del subtipo verrucoso. Esta asociación podría ser simplemente casual, pero en otras localizaciones, como en la cavidad oral, hasta un $0,5 \%$ de carcinomas epidermoides 
se desarrollan sobre un liquen plano ${ }^{2}$, por lo que sería necesario un estudio de series más amplias de casos desarrollados en genitales masculinos para intentar confirmar esa capacidad preneoplásica de la lesión. Dentro de los subtipos histológicos de liquen plano, el hipertrófico es el que más se asocia a carcinoma.

El carcinoma verrucoso suele plantear numerosos problemas diagnósticos al patólogo, ya que otras lesiones de la zona, tanto benignas como malignas, tienen características morfológicas similares. Los principales diagnósticos diferenciales incluyen el condiloma acuminado, el carcinoma epidermoide queratinizante, el condiloma gigante de Buschke-Löwenstein y el carcinoma condilomatoso como lesiones malignas, y la hiperplasia pseudocarcinomatosa como lesión benigna ${ }^{8}$. El carcinoma verrucoso puede diferenciarse de ellos por presentar crecimiento exofitico con un límite inferior muy bien definido, mínima atipia citológica y muy escasas mitosis. Además, la negatividad en la detección del HPV se ha descrito en un $66 \%$ de los carcinomas verrucosos, mientras que hasta el 100\% de los casos de carcinoma condilomatoso son positivos en algunas series $^{9}$, además de presentar papilas más irregulares. Es importante realizar un diagnóstico preciso, ya que el carcinoma verrucoso, aunque puede recidivar, raramente metastatiza.

Por otra parte, el liquen escleroso es una lesión papulosa blanquecina, que puede tener áreas escleróticas o telangiectasias, y que sangra con facilidad. Puede diferenciarse del liquen plano, que suele presentarse como pápulas brillantes de color morado, por la presencia al estudio microscópico de una submucosa homogeneizada, edematosa y con vasos sanguíneos congestivos.

Algunos factores causales relacionados con los carcinomas epidermoides de pene son la fimosis, mala higiene, tabaquismo, radiaciones ultravioletas, ausencia de circuncisión en la infancia, historia de verrugas o condilomas, y traumatismos o heridas $^{8,10}$. Nuestro paciente, tras el diagnóstico inicial en una biopsia de liquen plano, fue tratado con criocirugía para eliminar el resto de lesión. Hasta la fecha no se ha descrito una posible relación del daño causado por el nitrógeno líquido o por la biopsia previa con la carcinogénesis.
En resumen, se han descrito varios casos en los que un carcinoma epidermoide de pene se ha desarrollado sobre un liquen plano, aunque su número es por ahora muy pequeño como para poder establecer una relación causa-efecto.

\section{REFERENCIAS}

1. Bain L, Geronemus R. The association of lichen planus of the penis with squamous cell carcinoma in situ and with verrucous squamous carcinoma. J Dermatol Surg Oncol 1989 Apr; 15(4):413-417.

2. Worheide J, Bonsmann G, Kolde G, Hamm H. Squamous epithelial carcinoma at the site of lichen ruber hypertrophicus of the glans penis. Hautarzt 1991 Feb;42(2):112115.

3. Leal-Khouri S, Hruza GJ. Squamous cell carcinoma developing within lichen planus of the penis. Treatment with Mohs micrographic surgery. J Dermatol Surg Oncol. 1994 Apr;20(4):272-276.

4. Cox NH. Squamous cell carcinoma arising in lichen planus of the penis during topical cyclosporin therapy. Clin Exp Dermatol 1996 Jul;21(4):323-324.

5. Velazquez EF, Cubilla AL. Lichen sclerosus in 68 patients with squamous cell carcinoma of the penis: frequent atypias and correlation with special carcinoma variants suggests a precancerous role. Am J Surg Pathol 2003;27(11): 1448-1453.

6. Peyri E, Arango O. Liquen escleroso y atrófico del pene: lesión preneoplásica. Actas Urol Esp 2003;27(2):73-74.

7. Cubilla AL, Velazquez EF, Young RH. Pseudohyperplastic squamous cell carcinoma of the penis associated with lichen sclerosus. An extremely well-differentiated, nonverruciform neoplasm that preferentially affects the foreskin and is frequently misdiagnosed: a report of 10 cases of a distinctive clinicopathologic entity. Am J Surg Pathol 2004; 28(7):895-900.

8. Eble J, Sauter G, Epstein JI, Sesterhenn IA. World Health Organization Classification of Tumours. Pathology and genetics of tumours of the urinary system and male genital organs. $1^{\text {st }}$ ed. Lyon: IARC press, 2004.

9. Rubin MA, Kleter B, Zhou M, Ayala G, Cubilla AL, Guint WG, et al. Detection and typing of human papillomavirus DNA in penile carcinoma: evidence for multiple independent pathways of penile carcinogenesis. Am J Pathol 2001; 159:1211-1218.

10. Young RH, Srigley JR, Amin MB, Ulbright TM, Cubilla AL. Tumors of the prostate gland, seminal vesicles, male urethra, and penis. $3^{\text {rd }}$ series. Washington: AFIP, 2000.

Dr. C. Álvarez Álvarez

Servicio de Anatomía Patológica.

Hospital Montecelo

Mourente, $\mathrm{s} / \mathrm{n}$

36071 Pontevedra

e-mail: capialvarez@yahoo.com

(Trabajo recibido el 20 de abril 2005) 